\title{
Penyuluhan Sistem Kelistrikan Rumah Tangga untuk Masyarakat Kecamatan Babakan Cirebon
}

\author{
Noor Suryaningsih ${ }^{1}$, Dewanto Indra Krisnadi ${ }^{2}$, Ridwan Gunawan ${ }^{3}$ \\ 123 Jurusan Teknik Elektro, Fakultas Teknik, Universitas Pancasila \\ noor.suryaningsih@univpancasila.ac.id
}

\begin{abstract}
Abstrak
Pelaksanaan kegiatan pengabdian kepada masyarakat ini dilakukan kepada masyarakat Kecamatan Babakan Cirebon dan kegiatan pengabdian ini dilaksanakan dalam bentuk penyuluhan tentang sistem kelistrikan pada rumah tangga. Tujuan kegiatan pengabdian kepada masyarakat ini adalah melakukan pengabdian kepada masyarakat dengan cara penyuluhan untuk membuka wawasan dari masyarakat tentang keamanan pemakaian listrik terutama pada penggunaan peralatan listrik di rumah tangga. Pemahaman yang baik pada penggunaan peralatan listrik di rumah tangga, diharapkan masyarakat bisa menjaga agar peralatan-peralatan listrik di rumah selalu berfungsi dengan baik, aman dan hemat dalam pemakaiannya. Pelaksanaan pengabdian kepada masyarakat tentang sistem kelistrikan rumah tangga ini berjalan dengan lancar dan kegiatan pengabdian pada masyarakat ini memberikan hasil: meningkatnya pengetahuan peserta akan manfaat penggunaan listrik, meningkatnya pengetahuan peserta akan bahaya listrik, dan meningkatnya pengetahuan peserta terhadap penghematan pemakaian listrik sehari-harinya di rumah tangga.
\end{abstract}

Kata Kunci: peralatan listrik, listrik rumah tangga, penyuluhan, keamanan, hemat

\section{Counseling of The Household Electricity System to Kecamatan Babakan Communities, Cirebon}

\begin{abstract}
The implementation of community service activities is carried out to the people of the Babakan District of Cirebon and this community service activity is carried out in the form of counseling about the electrical system in the household. The purpose of this community service activities is to serve the community by counseling to open the knowledge from the community about the safety of electricity usage, especially on the use of electrical equipment in the household. A good understanding of the use of electronics appliances at home, it is hoped that the community can maintain that electrical appliances at home always function properly, safely and economically in their use. Implementation of community service to the household electrical system is running smoothly and community service activities produce results: increasing participant's knowledge of the benefits of using electricity, increasing participant's knowledge of the dangers of electricity, and increasing participant's knowledge of saving electricity consumption daily at home.
\end{abstract}

Keywords: electronics appliances, electricity, counseling, safety, saving

\section{PENDAHULUAN}

Di era modern seperti sekarang ini, listrik merupakan bagian terpenting dalam kehidupan manusia untuk membantu melakukan aktivitasnya sehari-hari. Melihat kebutuhan ini, konsumsi listrik masyarakat Indonesia setiap tahunnya terus meningkat sejalan dengan peningkatan pertumbuhan ekonomi nasional. Mengantisipasi meningkatnya pertumbuhan energi listrik diharapkan masyarakat bisa memahami sistem kelistrikan rumah tangga yang aman, hemat dan efisien di lingkungan rumah tangga.

Dengan mengetahui dan memahami tentang sistem kelistrikan yang paling sederhana khususnya di rumah tangga, diharapkan akan membuka wawasan dari masyarakat tentang 
Vol. 1, No. 2,

July 2020

pp. 79-84

e-ISSN:

2722-2004

\section{Title}

Counseling of The Household Electricity

System to

Kecamatan

Babakan

Communities,

Cirebon

Author

N. Suryaningsih,

D. I. Krisnadi,

R. Gunawan

keamanan pemakaian listrik terutama pada penggunaan peralatan listrik di rumah tangga. Pemahaman yang baik pada sistem kelistrikan dan penggunaan peralatan listrik di rumah tangga, diharapkan masyarakat bisa menjaga agar peralatanperalatan listrik di rumah selalu berfungsi dengan baik dan aman dalam pemakaiannya. Meningkatnya kepedulian ini diharapkan masyarakat akan lebih hemat dalam pemakaian energi listrik.

Melihat pentingnya keadaan di atas maka Jurusan Teknik Elektro Universitas Pancasila memandang perlu untuk melaksanakan pengabdian kepada masyarakat berupa penyuluhan tentang pemahaman sistem kelistrikan dan pemakaian peralatan listrik di rumah tangga. Pelaksanaan pengabdian kepada masyarakat ini diharapkan dapat memberikan pengetahuan kepada masyarakat tentang pemahaman penggunaan peralatan listrik rumah tangga yang baik dan aman serta diharapkan akan lebih peduli terhadap penghematan pemakaian energi listrik.

\section{METODE PELAKSANAAN}

Metode yang digunakan dalam pelaksanaan pengabdian kepada masyarakat ini adalah:

1) Presentasi: untuk menyampaikan sejumlah informasi mengenai pentingnya pemahaman penggunaan peralatan listrik rumah tangga, dibantu dengan membagikan materi presentasi kepada peserta.

2) Tanya jawab: dapat dilakukan selama proses pemaparan presentasi, dan setelah proses presentasi selesai.

3) Evaluasi: dilakukan melalui pembagian kuesioner kepada peserta untuk melihat pemahaman dari peserta terhadap pemahaman dari penggunaan peralatan listrik rumah tangga.

Pelaksanaan kegiatan pengabdian kepada masyarakat dilaksanakan di Kecamatan Babakan Cirebon pada tanggal 26 September 2019 diikuti oleh 30 peserta dengan didampingi oleh dua pembawa materi penyuluhan pada pelaksanaannya

Dalam pelaksanaan juga digunakan beberapa alat listrik untuk peraga seperti kabel, stop kontak, lampu dan peralatan listrik untuk rumah tangga lainnya.

\section{HASIL DAN PEMBAHASAN}

Pelaksanaan pengabdian kepada masyarakat tentang pemahaman sistem kelistrikan rumah tangga berjalan dengan lancar. Berdasarkan kesan dan pesan dari perwakilan peserta bahwa peserta sangat senang dengan kegiatan pengabdian ini. Mereka pada dasarnya sudah terbiasa untuk memakai peralatan listrik rumah tangga, tapi mereka tidak memahami tata cara pemakaian yang benar, aman dan hemat. Biasanya masyarakat cenderung hanya memakai saja, tanpa memahami apakah pemakaian peralatan listrik sudah benar dan aman.

Berdasarkan hasil wawancara, tanya jawab dan pengamatan langsung selama kegiatan pengabdian kepada masyarakat berlangsung, diharapkan kegiatan ini memberikan hasil sebagai berikut: 
KANGMAS: Karya Ilmiah Pengabdian Masyarakat, 1 (2), July 2020 - 81

http://journal.neolectura.com/index.php/Kangmas

a. Meningkatnya pengetahuan peserta akan manfaat listrik

b. Meningkatnya pengetahuan peserta akan keamanan pemakaian listrik

c. Meningkatnya pengetahuan peserta ini diharapkan juga akan meningkatkan kepedulian dan perilaku yang dapat menghemat pemakaian energi listrik di rumah tangga.

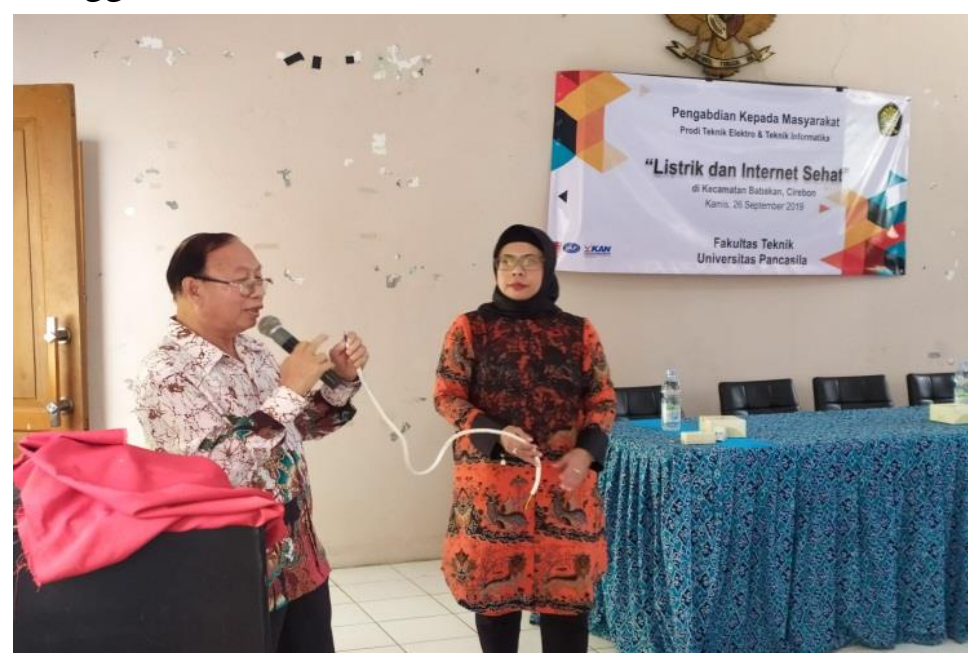

Gambar 1. Pelaksanaan penyuluhan PKM di Kecamatan Babakan Cirebon

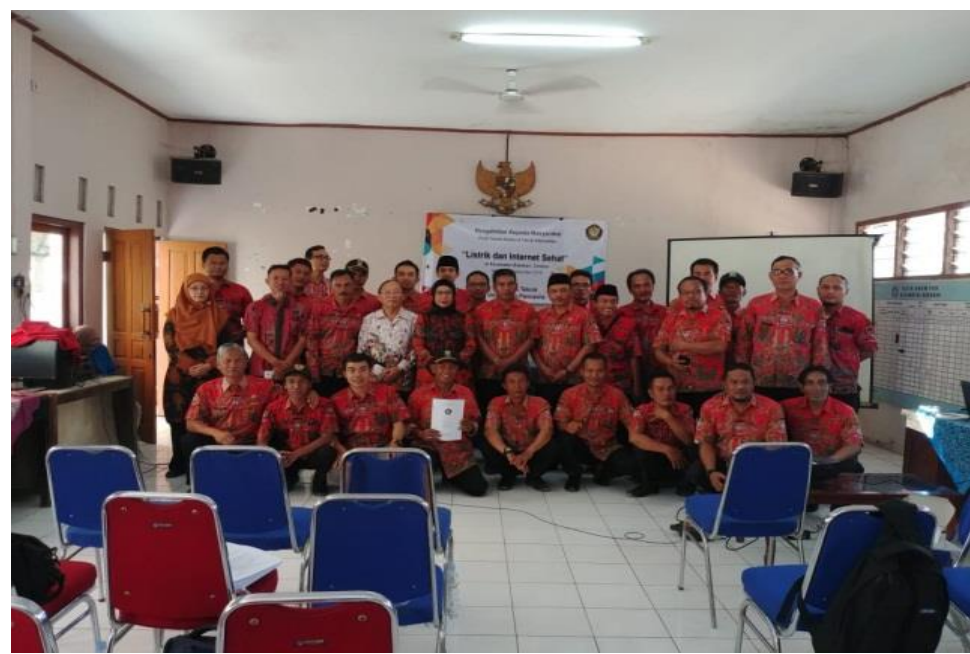

Gambar 2. Peserta penyuluhan PKM di Kecamatan Babakan Cirebon

\section{Analisa hasil kuesioner}

Setelah penyuluhan dibagikan kepada peserta kuesioner untuk diisi dan kemudian hasil dari pengisian kuesioner diolah dan menghasilkan keluaran sebagai berikut :

Keluaran dibagi menjadi dua bagian yaitu pemahaman tentang keamanan jaringan listrik dan pemahaman tentang kepedulian pemakaian peralatan listrik rumah tangga dengan kriteria penilaian dapat dilihat pada tabel 1.

Tabel 1. Kriteria Deskriptif Persentase

Interval

Kriteria 
KANGMAS: Karya Ilmiah Pengabdian Masyarakat, 1 (2), July 2020 - 82

http://journal.neolectura.com/index.php/Kangmas

Vol. 1, No. 2,

July 2020

pp. 79-84

e-ISSN:

2722-2004

Title

Counseling of The Household

Electricity

System to

Kecamatan

Babakan

Communities,

Cirebon

Author

N. Suryaningsih,

D. I. Krisnadi,

R. Gunawan

\begin{tabular}{cc}
\hline $0 \%<\% \leq 20 \%$ & Sangat rendah \\
$20 \%<\% \leq 40 \%$ & Rendah \\
$40 \%<\% \leq 60 \%$ & Sedang \\
$60 \%<\% \leq 80 \%$ & Tinggi \\
$80 \%<\% \leq 100 \%$ & Sangat tinggi \\
\hline
\end{tabular}


Penilaian dibagi menjadi lima kriteria penilaian yaitu sangat rendah, rendah, sedang, tinggi dan sangat tinggi. Kelima kriteria tersebut mempunyai rentang interval masing-masing dengan nilai antara 0 sampai dengan 100.

Dari Tabel 2 dapat dilihat bahwa pemahaman masyarakat terhadap keamanan jaringan listrik sebesar $60 \%$ setelah dikonsultasikan dengan kriteria persentase yang telah dibuat persentase tersebut termasuk dalam kategori sedang $(40 \%<\% \leq 60 \%)$. Kemudian kedua komponen penyusunnya, yaitu tentang perilaku yang mengancam keselamatan jiwa persentasenya sebesar $62,5 \%$ juga termasuk dalam kategori tinggi. Sedangkan satu komponen yang lain, yaitu tentang perilaku yang dapat menyebabkan kebakaran, dan kerusakan jaringan persentase yang diperoleh sebesar $57,5 \%$ dan termasuk dalam kategori sedang $(40 \%-60 \%)$.

Tabel 2. Pemahaman Tentang Keamanan Jaringan Listrik

\begin{tabular}{clccc}
\hline No & \multicolumn{1}{c}{ Komponen } & n & N & \% \\
\hline 1. & $\begin{array}{l}\text { Perilaku yang mengancam } \\
\text { keselamatan jiwa }\end{array}$ & 25 & 40 & 62,5 \\
2. & $\begin{array}{l}\text { Perilaku yang dapat } \\
\text { menyebabkan kebakaran, dan } \\
\text { kerusakan jaringan }\end{array}$ & 23 & 40 & 57,5 \\
\hline $\begin{array}{l}\text { Pemahaman tentang keamanan } \\
\text { jaringan listrik }\end{array}$ & 48 & 80 & 60,0 \\
\hline
\end{tabular}

Dari Tabel 3 dapat dilihat bahwa pemahaman masyarakat terhadap kepedulian pemakaian peralatan listrik rumah tangga sebesar $61 \%$ setelah dikonsultasikan dengan kriteria persentase yang telah dibuat persentase tersebut termasuk dalam kategori tinggi $(60 \%-80 \%)$. Kemudian ketiga komponen penyusunnya, yaitu tentang perilaku yang mengancam keselamatan jiwa persentasenya sebesar $68 \%$ juga termasuk dalam kategori tinggi. Sedangkan kedua komponen yang lain, yaitu tentang perilaku yang dapat menyebabkan kebakaran, dan kerusakan instalasi persentase yang diperoleh sebesar 56\% termasuk dalam kategori sedang (40\% - 60\%), demikian juga dengan komponen perilaku yang dapat menyebabkan kerusakan peralatan persentase yang diperoleh sebesar $60 \%$ juga termasuk dalam kategori tinggi.

Tabel 3. Pemahaman Tentang Kepedulian Pemakaian Peralatan Listrik

\begin{tabular}{clccc}
\hline No & \multicolumn{1}{c}{ Komponen } & n & N & \% \\
\hline 1. & $\begin{array}{l}\text { Perilaku yang mengancam } \\
\text { keselamatan jiwa }\end{array}$ & 27 & 40 & 68 \\
2. & $\begin{array}{l}\text { Perilaku yang dapat menyebabkan } \\
\text { kebakaran, dan kerusakan instalasi }\end{array}$ & 28 & 50 & 56 \\
3. $\begin{array}{l}\text { Perilaku yang dapat menyebabkan } \\
\text { kerusakan peralatan }\end{array}$ & 30 & 50 & 60 \\
\hline $\begin{array}{l}\text { Pemahaman tentang Kepedulian } \\
\text { Pemakaian Peralatan Listrik rumah } \\
\text { tangga }\end{array}$ & 85 & 140 & 61 \\
\hline
\end{tabular}


KANGMAS: Karya Ilmiah Pengabdian Masyarakat, 1 (2), July 2020 - 84

http://journal.neolectura.com/index.php/Kangmas

Vol. 1, No. 2,

July 2020

pp. $79-84$

e-ISSN:

2722-2004

\section{Title}

Counseling of The Household

Electricity

System to

Kecamatan

Babakan

Communities,

Cirebon

\section{Author}

N. Suryaningsih,

D. I. Krisnadi,

R. Gunawan

\section{Faktor pendukung dan penghambat}

Beberapa faktor yang mendukung terlaksananya kegiatan pengabdian pada masyarakat ini adalah besarnya minat dan antusiasme peserta selama kegiatan, sehingga kegiatan berlangsung dengan lancar dan efektif. Pihak perangkat desa juga mendukung kegiatan ini. Sedangkan faktor penghambatnya adalah keterbatasan waktu penyuluhan serta masih kurangnya ketersediaan peralatan pendukung yang digunakan dalam pengabdian kepada masyarakat ini.

\section{SIMPULAN}

Dari kegiatan pengabdian kepada masyarakat yang dilakukan oleh Jurusan Teknik Elektro Universitas Pancasila ini dapat disimpulkan bahwa di masyarakat kecamatan Babakan Cirebon tingkat pemahaman tentang keamanan jaringan dan kepedulian pemakaian peralatan listrik rumah tangga sudah masuk kategori sedang dan tinggi dengan nilai $60 \%$ dan $61 \%$. Meningkatnya pengetahuan dan kepedulian masyarakat tentang sistem kelistrikan rumah tangga ini diharapkan akan meningkatkan perilaku masyarakat yang dapat menghemat pemakaian energi listrik di rumah tangga.

\section{DAFTAR PUSTAKA}

Badan Standardisasi Nasional, (2011). Persyaratan Umum Instalasi Listrik 2011 (PUIL 2011). Jakarta: Kementerian Energi Sumber Daya Manusia (ESDM)

Ekarini, D. (2015). Panduan Praktis Gaya Hidup Hemat Energi. Jakarta: Kementerian Energi Sumber Daya Manusia (ESDM).

Gatut S, Sasi A, (2007). Kiat Hemat Bayar Listrik. Depok: Penebar Swadaya

Rifai, A. (2014). Buku Pintar Mengatasi Listrik di Rumah. Bandung: Gema Buku Nusantara. 